\title{
Models and Metaphors in Groupware: Towards a Group-Centered Design
}

\author{
Gloria Mark and Peter Mambrey
}

\author{
GMD FIT \\ German National Reserch Center for Information Technology \\ Institute for Applied Information Technology \\ Research Group CSCW \\ Schloß Birlinghoven \\ 53754 Sankt Augustin, Germany \\ E-mail: \{Gloria.Mark,Peter.Mambrey\}@gmd.de
}

\begin{abstract}
This paper reports on user experiences with the introduction of a groupware system in a government ministry. Our findings suggest that users understood the system as supporting collaboration, yet they had difficulties in understanding and using the groupware due to: 1) the lack of corresponding representation in the user's actual working life, 2) the reluctance to change personal work habits in order to develop shared group conventions, 3) the organization's influence through strict codes and procedures, and 4) the different models of cooperative work that users and designers developed. We recommend that designers and practitioners focus training and analysis on developing a shared representation of the group toward its work and the groupware system.
\end{abstract}

KEYWORDS groupware, metaphor, mental model, organizational influences, user studies

\section{INTRODUCTION}

Learning to work with a groupware system is a complex feat. In recent years, some attention has been directed toward the user's cognitions as an important approach in which to understand how the user comprehends and works with a new system (e.g. Davidson, 1996; Orlikowski, 1992, Rogers and Ellis, 1994). A user's acceptance and behavior toward a technology has been proposed by Orlikowski and Gash (1994) to be related to the clarity of the user's understanding of the technology.

Training people in a groupware system is difficult since there are few experiences reported with actual groupware use. Those that have generally report difficulties that users have in adapting to technology (Bowers, 1994; Bullen and Bennett, 1990; Grudin,
1988; Orlikowski, 1992; Rogers, 1994). The lack of user experiences makes it difficult to develop a conceptual teaching model which can be used as a basis to introduce groupware.

The purpose of this paper is to report on user experiences during the introduction of a large groupware system, PoliTeam. Our focus of the user investigation was to discover ideas and attitudes that the users had developed of the system and of their collaborative process. When the project started, we realized that users would be faced with difficult problems: they would not only have to learn new functionality (and for most users, learn basic computer skills as well), but they would also have to learn new work patterns which were not based on anything similar in the users' actual working life. 


\section{THE ORGANIZATIONAL SETTING}

\subsection{System use}

In 1991, the German government voted to move the capital from Bonn to Berlin. Not all federal agencies and ministeries will relocate at once; thus, departments will be distributed between the two cities during the move. The goal of the PoLITeam groupware system is to connect government employees through telecooperation between Bonn and Berlin. An existing groupware system (LinkWorks) was chosen and adapted to specific user and situation requirements. (For further information, see Sohlenkamp et al., forthcoming).

Prototypes were implemented in three areas of the government: the Federal Ministry of Family Affairs, Senior Citizens, Women, and Youth (FM), the State Representative body of Mecklenburg-Western Pomerania (SR), and the Ministry of Justice (MJ) in Schwerin. The project began in May 1994, and the system has been installed since January, 1995. The design approach integrated three different aspects: evolutionary cycling, direct designer-user contact, and user advocacy (Mambrey et al., 1996).

Although all locations have the full system installed, use is concentrated in particular applications, depending on the work practices of each ministry. In the FM, there are currently 10 users: 7 are employees responsible for specific content areas of the ministry, and 3 are typists in the central typing pool. The employees collaborate using the shared workspace, (e.g. writing speeches for the minister) and they exchange documents with each other and with the typing pool, who type intermediate and final versions.

In the SR, there are currently 8 unit leaders who use the system. Collaboration is primarily with the "Reference" application which allows people to work on a shared electronic document remotely and asynchronously. The users use this system to record votes for their respective ministers. The German House of Representatives meets every two weeks, and discusses approximately 80 issues. The unit leaders use the groupware for information dissemination and the Reference application to record their votes on 80 shared documents, one per issue.

The third location, the MJ, has approximately 20 users, mostly lawyers. Because of the distance from Bonn, site visits and interviews were conducted, but less observation was possible at this site than at the others.

\subsection{Method of observation}

We present our observations from a collection of experiences: workshops, site visits, discussions between designers and users, and user interviews. One of the authors was involved in the project since its inception and participated as an observer in design workshops. work requirements analyses, training workshops, a number of structured background interviews, regular user interviews, and simply "being present and chatting with the users". Transcripts were taken for most of these activities. This field work was done continually since May 1994. This author also actively discussed work scenarios with the users. In addition, a study was conducted to identify how the government's formal code of procedures (GGO) actually was implemented in the organization and to what extent it was followed by the employees. Both authors conducted additional interviews with users, after the system was in use about 6 months, and were observers in workshops and design discussions. The goal in observing the work requirements analysis was to try to understand what the users' work practices were, and how the users understood their working relationships.

\section{MODELS AND METAPHORS OF GROUPWARE}

Although with more user experiences we can better define a normative mental model of groupware, we began by following Johnson-Laird's (1983) notion: mental models are internal representations that are developed through experience. Mental models:

...play a central and unifying role in representing objects, states of affairs, sequences of events, the way the world is, and the social and psychological actions of daily life $(p$. 397).

A mental model for a groupware user is not only a representation of how the system works, but it also contains a representation of the group work with the system. Although we discuss models of groups, it is important to emphasize that mental models are individual constructs. A person's mental model of a system is one's own representation of how and why the system works: it can generate descriptions of the purpose and form of the system, it can explain its 
functions, and can be used to make predictions about future states. Models develop naturally. They need not be technically accurate, but they must be functional and fit for a purpose (Fischer, 1991).

People have different perspectives, and this often becomes evident when people use groupware. Designers' perspectives have been observed to be different than those of users (Davidson, 1996; Orlikowski and Gash, 1994). The groupware use may be affected not only by users' understanding or misunderstandings of the system, but also by different mental models that group members have about the group and its goals. Generally, when people work in groups, they develop a set of common norms, assumptions, goals, and procedures, and members strive to attain a common understanding of these as the group becomes a reference for them (Newcomb, 1959). Since people are individuals, it is not possible that their cognitive representations can be identical, yet if they are interacting in a group sharing the same experiences, common perceptions develop (Fiske and Taylor, 1984). Especially when working together in an organization, people develop similar representations: experiences, activities, or attitudes which they recognize as common, referred to as "shared understanding" by Schein (1990). These can be centered on task goals, knowledge about the work and organization, or their informal and formal social communication, etc. However, when different representations among group members exist, they can become manifest as problems when a new technology is implemented (Orlikowski and Gash, 1994).

Metaphors can be vehicles to develop mental models, to explore them, and to communicate them. Metaphors enable us to create new perceptions, to conceptualize, and to think imaginatively about artifacts and mentifacts as well. As exploratory tools, metaphors can be used to help people restructure their models and generate new ideas, and can be valuable in system design (Mambrey and Tepper, 1996).

As researchers, we are trying to understand the models of the users. The problem with mental models is that they are individual, and often difficult to externalize. Unlike a scientific conceptual model of a system, which can be operationalized and described with formal notation, mental models are not standardized. Metaphors can provide valuable clues to the researcher as to what a user's model might be. For example, the researcher can observe what metaphors the person applies to learn new experiences, and how literally it is applied. A person may also explain an operation with the wrong metaphor, indicating that the user has a false model of the process. For example, one might believe that they "own" a document. enabling them to change access rights, when in effect, one is actually using it through WYSIWIS.

\section{THE USERS' MODELS}

In this section, we present selected scenarios which illustrate the range of models that the users developed.

\subsection{Models of cooperation}

Whereas before the implementation of the system. users used the expression "cooperative work" in an abstract and general way, after the users began working with the system, they began using the term "cooperative work" in a more personal, however sometimes idiosyncratic way. Thus, we found that users developed different notions of cooperation.

During an instructional workshop, the users referred to "searching" for a file as a cooperative activity, since this action may be performed if your colleague asks you for a document. This was an idea which did not occur to us. One unit leader's view of cooperation was very feature specific; using the Reference function to record votes, or looking to see whether others are logged on made him feel that he was working cooperatively, or "electronically connected". Otherwise, he did not have a sense of working cooperatively with others. To another unit leader, his model of the collaborative nature of the system was a function of his work role. As a coordinator, the system is a tool that he uses to distribute work; it saves time for him. As a coworker. it is a "shared" system, where he uses it in the same capacity as his colleagues, and as an information provider, it is a communication device, to disseminate information.

However, the users also expressed wanting to put a limit on cooperation. This occurred during a workshop where the users were taught a new version of the Search tool. The Search tool is designed so that a found object automatically is produced as a Reference. As a Reference, anyone searching and finding this object (searching is limited to access rights) could make changes to it and it appears on the original. When this feature was demonstrated to the users, they protested strongly. They claimed that this idea went against their 
idea of cooperative work. They did not want to allow the complete freedom for all to make changes to a found object. They felt that the original should remain intact, in the owner's "desktop space". They preferred that the found object should be a copy instead, where making changes does not affect the original. The automatically produced Reference was a design feature in Linkworks, and the designers felt that the design philosophy was to promote sharing and strengthen groupwork. We interpret the users' reaction as an expression of "bounded" cooperation, contrary to what the designers expected.

Different ideas about cooperation also developed between the unit employees and the typists in the FM. To the unit employees, who do conceptual work such as writing speeches, their interaction with the central typing pool is not cooperation. To them, typing is a "mechanistic" process like reformatting, and they feel there is no "add-on" value from the typist. However, the typists feel that they are a necessary part of groupwork and cooperation. The typists believe that they are "manipulating" the documents, which makes their jobs a part of the group work. Here the metaphors that the employees use to convey group work conflicts with the typists' notion. The "add-on" metaphor of the civil servants assumes intellectual modification is a requirement for group work. As will be discussed shortly, this differing notion of cooperation translated into differences in conventions of system use.

\subsection{Models of the organization}

We found that many aspects of the organization were applied as metaphors by the users in their use of the groupware. These include the idea of responsibility, which is associated with one's position in the vertical line, and with the idea of private and public work that is officially prescribed in the government's codes. This formal set of codes, the GGO, are strict regulations about how work is to be organized and conducted.

\section{Organizational responsibility}

In a study of the organizational hierarchy, Mambrey and Robinson (1994) found that the employees hold specific models of the hierarchical direction: cooperation is associated with the horizontal strata, is self-organized, and revolves around the task, whereas coordination and "controlling of work" is associated with vertical lines. Responsibility is a key difference. In horizontal cooperation, the responsibility is shared by the group. In vertical cooperation, the responsiblity is shifted to the upper ranks, which relieves the employee of the responsibility. Using the metaphor "chiefs" in connection with work indicates always a vertical structure of "those above us" who are responsible.

We see this notion of responsibility affecting the employees' use of the shared workspace in the FM. People maintain their personal workflows that they are responsible for on the shared workspace, but no one maintains the group work that no one is personally designated responsible for. This collection, consisting of old mail, memos, old speech versions, etc. has simply built up on the shared workspace like a junk drawer. However, sometimes users need material from it and they complain that they cannot find it. What we see happening here is a 'social dilemma' (Dawes, 1980). In a social dilemma, each group member must decide to cooperate or not to cooperate for all members to receive benefits. One can be a 'good citizen', as in the case of contributing to public television, or one can be a 'free rider', and hope that others will contribute to keep public television alive. If all are free riders, as in the case with the shared workspace, then the work does not get done, and no one receives the benefits of having an organized workspace.

However, in contrast, all the users are careful to maintain a common address book which they all receive benefits from, consistent with Grudin's (1988) observation. The address book tool has a closer representation to what is familiar in the paper world than does a shared workspace; the benefits of having a common address list may be easier to understand and appreciate than the benefits of an organized workspace.

One brief note of observation: when a person is personally responsible for shared work that is transferred through the workspace, then the documents are maintained (e.g. the exchange process of a speech between the typist and the employee who is responsible for it). The pattern we observe is that if it is a group member's responsibility to make sure that the task is completed, then they take care that the work is done. Otherwise, they look for personal benefits.

\section{Organizational property}

Acording to the GGO, only official documents exist. The only work allowed is official work, done on behalf of, and by rules that substitute for the Minister in person. The public nature of work is emphasized in the detailed work flow process, e.g. the specific path that 
an incoming letter takes, and how it will be archived and therefore remain public for several years (Mambrey and Robinson, 1994).

In work practice, the hierarchical, strictly formal bureaucracy is intertwined with officially "invisible", informal work. A ministry is a vivid social construction, which needs the self-organized informal interaction of persons and formal structure to work (Mambrey and Robinson, 1994). Despite this idea of public work within the organization, the employees have their own private work which refers to privacy during the process of doing a task, such as writing a speech. The early versions are considered private work.

We found that this notion of private and public work was reflected in the users' use of their physical desks. Everything which is within a drawer is strictly private; everything which is upon the desk top is public, at least to the colleagues of the unit. You do not need to control access to your desktop since everyone who is allowed to walk around in the office area can look at your desk top. By social protocol nobody searches in your drawer, which in addition often is locked by a key.

The situation is quite different if we change from the physical world to the electronic world. Because of the "official" nature of public work, the users wanted to be very clear about maintaining a distinction between public and private work. In the requirements analysis, users requested that they have a personal desk drawer in the system to store their private documents (although this requirement was against the formal GGO). For example, one unit leader has special links to the ministry of the coalition in Schwerin which is headed by a social democrat. He of course does not want that all of his work is transparent, and is not interested that all his work is seen by his department head, who is in the CDU, the other party in the coalition. The users are very careful as to which documents they put in the shared folder, knowing that all would have access to it, e.g. "I put only files into this folder, that I think are really public". The users consider the working process as private, and want the system to allow them to maintain their privacy during this process.

\subsection{Models of personal work}

We also found that people were reluctant to give up their personal style of working, which is necessary in order to establish some shared group conventions.

\section{Different work styles: storage and "piles"}

One of the authors made sketches of, and talked with users about their desktops, in order to identify common patterns. Desktops exist which are nearly blank; other desktops are overloaded with all kinds of artifacts of the office work. Nevertheless all the different groups share a common storage principle: they think and organize in piles (of documents). The piles are generally not arbitrary; there is a structure according to the owner's personal scheme: usually piles affiliated with tasks. For example, for one unit head, the following rules existed: urgent and important piles lay close to the center, urgency overrules importance, and future work is situated at the periphery of the desk. Each pile itself is structured by importance (top being most important) rather than chronological ordering.

In using the shared workspace, users had to learn a new way of structuring their electronic desktops. The task of the users was to transfer a 3-D structuring system that they were used to in the paper world, into building a 2-D structure with nested documents. The users know their own desktops; it is intuitive to them where documents are stored, and search is easy. However, not only did users report difficulty in adapting to an electronic desktop structure, but also with changing their personal organization of work to adapt to a shared group organization.

\section{Personal information structuring}

The users in the FM strongly rejected the idea of having a shared common organization of information. The unit employees prefer nesting their documents in a hierarchical structure on the shared desktop; the typists want all information to be stored on one level without hierarchical structuring. It is our speculation that both may be applying analogy from the paper world to the electronic desktop. The employees of the unit, as described above, structure their information on their physical desktops in pile arrangements. The typists, by analogy, may be using the same physical structuring that they use in the paper world: an "in-box" and "outbox" on their desks. One employee reflected her resistance to change by commenting that people are "creatures of habit". What we observe is that users are pulling their files out of the joint registrar (i.e. the "nonjunk drawer") on the shared desk tops and storing them in their personal archives. In fact, the users also report that they do not even want to see files or folders 
of colleagues on the shared desk top because this is viewed as unneccessary infomation overload.

\subsection{Models of electronic work}

We found a very different type of problem with the users in the SR. The Reference application, primarily used to record the votes of ministers, was difficult to learn and understand. Moreover, a useful metaphor for the Reference could not be developed. In the following, we discuss some of these conceptual difficulties.

\section{What you see is not what you own}

The users did not understand the distinction between being the owner and possessor of a document. The users believed that if the document appeared on their screen (The WYSIWIS feature of the Reference), then they were owners, with full ownership rights. Here are common errors which illustrate the incorrect model that the users had of the application. The owner produces the document with public access rights. It is then forwarded to another unit leader who opens it, and changes the access rights to private. He later wants to work on it but can't open the document because the access profile belongs to the owner, and not to him. Another common error is that a user may try to erase the Reference, thinking all others would also lose their documents. If the user is not the owner, he only succeeds in erasing his own Reference.

\section{What you don't see is what you have}

Applying analogous reasoning of paper documents to electronic documents can lead to misunderstandings. Our service staff had to help both FM and SR users who could not find documents although they were sure that they existed electronically. It turned out that documents "existed" for the users only when they could see them on the electronic desk top, e.g. as an icon or as an abbreviation. Although elaborate search mechanisms exist (e.g. a Search tool) they relied on the well known structure of the paper world for analogy, i.e. you identify papers by their appearance and only if you physically are in possession of them can you manipulate them. The users had difficulty understanding that they could manipulate a file without visually seeing the document. For example, the access right of a folder can be changed from public to private, which affects all files which are included in the folder. When a document becomes private, then it does not appear visually on the desktop any more to people who do not have the access rights.

\section{DISCUSSION}

We found that users carried many metaphors from the paper world into the electronic world. These metaphors came from the organization, from their physical desktops, and from their experiences with paper documents. Unfortunately, too many of these "paper world" metaphors were applied too literally. Despite the intensive training, it proved to be very difficult to communicate the idea of the Reference to the users. We surmise that the reason was that the Reference application had no familiar representation in their "paper world". The role of prior experience cannot be underestimated in the development of models of new processes, since prior experience can help guide the user on what might be appropriate strategies in learning a system (Carroll and Thomas, 1982).

Designers and users had different perspectives of group work: different expectations about learning and understanding a remote asynchronous shared application, and in developing shared group conventions. This suggests to us that designers must develop an appropriate representation of the group, its work practice, and realistic expectations about what the group can accomplish.

Different perspectives also existed between the employees and typists of the FM: different notions of cooperation, different file structuring conventions, and lack of maintainance of the shared workspace. A groupware system brings people together to form new types of work relationships. Designers and trainers must consider these work relationships, and suggest common discussions if necessary when issues arise.

Two very basic yet different kinds of problems emerged in the different ministries. In the SR, the main problem for the users seems to be the lack of understanding of the system, leading to frustrating errors (one user described the Reference as his "main nemesis"). In contrast, in the FM, although the users also made errors with the system, the main problem seems to be due to the nature of the work group collaboration. We attribute the inflexibility in adapting to a shared group convention, and the lack of maintenance of the public space, more to the work group than to the nature of the system. The work groups are different in the two ministries. In the SR, 
cooperation using the system is horizontal, among unit leaders at the same level of the hierarchy. In the FM, cooperation is between employees and typists who have many differences: different jobs, education levels, career path orientations, salaries, etc. which could certainly play a role in the development of the problems that we observed.

It is our general belief that users viewed the system as collaborative, rather than single-user, in contrast to Orlikowsi's (1992) finding with Lotus Notes. Unlike our users, the Notes users did not receive intensive training in the collaborative aspects of the system, and system metaphors were not used.

The strict codes and procedures of the organization influences the people's work habits, and this in turn, influences their use of the system. Whereas Orlikowski (1992) reports that the competitive and individualistic nature of the organization was against supporting cooperation, our finding was similar, except that people's models of cooperation is associated with particular horizontal lines of the organization's hierarchy. The vertical line, which connotes career paths, and superiors, competes with the notion of working together cooperatively. The model of responsibility which the organization fosters also surfaces with the use of the shared workspace. The users do not maintain documents unless a specific individual is responsible for them. Unlike Grudin's (1988) dilemma, only one or a few need to make the effort to organize material and all would benefit from an organized shared workspace where documents would be easy to find.

We feel that the users were able to accept problems, such as the constant system errors they made, because they saw real benefits in using the system, such as in saving time. One unit leader in the SR claimed that he received the electronic work about one day earlier than he would ordinarily receive the paper work. As a coordinator, this is a big relief for him. The employees in the FM reported a faster turn-around time for working and reworking versions of documents, using the shared workspace.

\section{DEVELOPING SHARED MODELS}

In this paper, the lesson that we have learned is that is essential to consider the group's shared representation of the new technology. We propose that designers use a group-centered design approach, where system design and training emphasizes an appropriate shared representation of the group members. We present some suggestions in this direction.

- Initial experiences play an important role in forming an appropriate mental model. It is more difficult to change attitudes later, than earlier.

- Models must be continually developed over time, since groups need time to develop common factors: assumptions, understanding of roles, procedures, etc.

- Designer-user communication must consider group issues. This could also be done using user advocates, an approach which we found to be effective, since the user advocates developed close working relationships with the users (Mambrey et al., 1996).

- Trainers must support the design process through the constant training and reinforcement in the idea of collaborative work with the system. From our experience, we found training in collective groups to be valuable.

- In performing work analyses, distributed cognition can be a useful means to identify the shared and individual knowledge of groups, and how it is communicated, adapted, and used (Rogers and Ellis. 1994).

- Metaphors can help develop common experiences. as with the case of the PoliTeam metaphor (i.e. "teams between cities"), the project name which we use to build a social identity for users and designers. Metaphors can be valuable teaching aids, but only when they are the right ones. From our experience, different perspectives can result in the selection of the wrong metaphor. Not all metaphors are appropriate, and metaphors in the paper world cannot transfer literally to the electronic world. We lose information when information is transferred from the paper to the electronic world and for this reason, a literal mapping from source to target can create confusion. Metaphors are highly contextual, are tied to experience, are nonliteral expressions, and must be understood so.

This study has raised challenging questions for us. What is the implication for groupware if users have different notions of cooperation? How can groups develop ideas about group work that are less under the influence of the organization and more relevant for the group? How can personal conventions and work styles be integrated to create standards for a shared group work style when it is required in groupware? What are appropriate metaphors to represent work processes which have no representation in the workers' actual 
life? We intend with further observation to gain more insight into what these early findings might mean.

\section{Acknowledgements}

The authors would like to thank the following people for their valuable comments and insights: Wolfgang Dzida, David England, Margarete Boos, Richard Bentley, Alfred Kobsa, and Klaas Sikkel.

\section{References}

1. Bowers, J. (1994). The Work to Make a Network Work: Studying CSCW in Action, in Proceedings of CSCW '94 Chapel Hill, October 1994, ACM Press, 287-298.

2. Bullen, C. and Bennett, J. (1990) Groupware in Practice: An Interpretation of Work Experience. Proceedings of. CSCW '90, Los Angeles, October, 1990, ACM Press, 291-302.

3. Carroll, J.M. and Thomas, J.C. (1982). Metaphors and the Cognitive Representation of Computing Systems. IEEE Transactions On Systems, Man, And Cybernetics, Vol. SMC-12, No. 2.

4. Davidson, E.J. (1996). Framing Information Systems Requirements: An Investigation of Social Cognitive Processes in Information Systems Delivery. Dissertation, Massachusetts Institute of Technology.

5. Dawes, R.M. (1980). Social dilemmas. Annual Review of Psychology, 31, 169-193.

6. Fischer, G. (1991). The importance of models in making complex systems comprehensible. In Tauber, M.J. and Ackermann (Eds.), Mental Models and Human Computer Interaction 2, North-Holland.

7. Fiske, S.T. and Taylor, S.E. (1984). Social Cognition. New York: Random House.

8. Grudin. J. (1988). Why CSCW applications fail: problems in the design and evaluation of organizational interfaces. Proceedings of $\mathrm{CSCW}$ '88, ACM Press, 85-93.

9. Johnson-Laird, P. (1983). Mental Models. Cambridge: Harvard University Press.
10. Mambrey, P., Mark, G., and Pankoke-Babatz (1996). Integrating User Advocacy into Participatory Design: the Designers' Perspective. In J. Blomberg, F. Kensing, E. Dykstra-Erickson (Eds.) Proceedings of the Participatory Design Conference'96, Cambridge, M.A., 251-261.

11. Mambrey, P. and Robinson, M. (1994). Preparing a speech for the minister: notes towards understanding the role of artifacts in a flow of work. Unpublished manuscript.

12. Mambrey, P. and Tepper, A. (1996). Metaphors and System Design. In P. Hoschka (ed.): Assisting Computer. A New Generation of Support Systems. Lawrence Erlbaum Assoc. Hillsdale N.J.

13. Newcomb, T.M. (1959). Individual systems of orientation. In S. Koch (Ed.), Psychology, A Study of Science, Vol. 3, New York: McGraw-Hill.

14. Orlikowski, W.J. (1992). Learning from Notes: Organizational Issues in Groupware Implementation, Proceedings of $\mathrm{CSCW}$ ' 92 , Toronto, ACM Press, 362-369.

15. Orlikowski, W.J. and Gash, D.C. (1994). Technological frames: making sense of information technology in organizations. ACM Transactions on Information Systems, (12) 2, 174207.

16. Rogers, Y. (1994). Exploring obstacles: integrating $\mathrm{CSCW}$ in evolving organisations. Proceedings of CSCW '94, Chapel Hill, Oct. 1994, ACM Press, 67-77.

17. Rogers, Y. and Ellis, J. (1994). Distributed cognition: an alternative framework for analysing and explaining collaborative working. Journal of Information Technology (9), 119-128.

18. Schein, E. (1990). Organizational Culture and Leadership. San Francisco: Jossey-Bass.

19. Sohlenkamp, M., Mambrey, P., Prinz, W., Fuchs, L., Syri, A., Pankoke-Babatz, U., Klöckner, K., and Kolvenbach, S. (Forthcoming). Supporting the distributed German government with PoLITeam. International Journal of Multimedia Tools and Applications. 